Reviews in Digital Humanities

\title{
Review: Louisiana Slave Conspiracies
}

Keerti Arora ${ }^{\mathbf{1}}$, Anna Lawrence ${ }^{\mathbf{1}}$

${ }^{1}$ University of Texas at Austin

Published on: Feb 08, 2021

License: Creative Commons Attribution 4.0 International License (CC-BY 4.0). 


\section{Project}

Louisiana Slave Conspiracies

\section{Project Leads}

Bryan Wagner, University of California, Berkeley

Patty Frontiera, University of California, Berkeley

Shadrick A. Small, University of California, Berkeley

Jenelle Thomas, Christ Church, Oxford University

\section{Project URL}

https://lsc.berkeley.edu/

\section{Project Reviewers}

Keerti Arora, University of Texas at Austin

Anna Lawrence, University of Texas at Austin

\section{Project Overview}

\section{Brian Wagner, Patty Frontiera, Shadrick A. Small, and Jenelle Thomas}

Louisiana Slave Conspiracies is an interdisciplinary and collaborative research project dedicated to preserving, digitizing, transcribing, translating, publishing, and analyzing manuscripts related to two slave conspiracies organized at Pointe Coupée in the Spanish territory of Louisiana in 1791 and 1795. Our research team has transcribed and translated thousands of manuscript pages in French and Spanish and created bibliographic, demographic, geospatial, and forensic data about documents, persons, places, events, and assertions relevant to these conspiracies. Our website employs a custom facing-page display to present facsimile images alongside transcriptions and translations, permitting users to search, browse, and navigate among documents, a census, and a digital map. Our intended audience includes not only specialists in Louisiana history, the French and Spanish empires, and the Age of Revolution, but also a range of scholars in the humanities and social sciences who have confronted the issue of unreliable documentary evidence as they have sought to understand slave resistance. This is a challenge known to anyone who has thought about the politics practiced not only by enslaved people but also by peasants, Indigenous, and other subaltern groups.

\section{Project Review}

\section{Keerti Arora and Anna Lawrence}


Louisiana Slave Conspiracies (LSC) enables a self-directed, alternative, multimodal way of learning about the events surrounding the 1791 and 1795 Pointe Coupée conspiracies in Louisiana. Led by Bryan Wagner, Patty Frontiera, Shadrick A. Small, and Jenelle Thomas, this project adds an invaluable digital resource to historiographic projects on slavery and slave insurrections. The website creates and communicates creative, polyvocal historical scholarship to tell the history of enslaved peoples' efforts to free themselves from the ownership of Julien Poydras and others in the surrounding area. Betrayed before the onset of the revolt, 23 of the 57 would lose their lives after being tried for conspiracy.

Unlike articles that relay information linearly, this interactive digital project presents the events, people, and places associated with the event under tabs that allow users to switch between description, source documents and their translations, and searchable databases of people and places. LSC also responds to contemporary concerns over data reduction by presenting its visualizations with a reflexive assertion that they are based on expert and local interpretations and contributions only. Users first encounter a birds-eye view of all the places of interest in a condensed map. These visualizations can be accessed through an interactive map that gives users the agency to investigate and selectively retrieve information as they explore. Users can choose a place type, place name, and conspiracy from drop-down menus to follow their interests. Each page is interlinked via hyperlinks with other information on the site, giving the site a web-like feel. Unlike the possibilities afforded by print-era historical scholarship, accessing primary source documents this way enables users to ask questions along multiple tangents in less time.

Users can imagine possibilities through the organization, reception, and interpretation of the events and the trials that followed. The creators don't give definitive interpretations/arguments about what the data means. Instead, they present scanned documents alongside their transcription and translations, allowing users to evaluate historical sources themselves. Users find a plethora of declarations, acts, confessions, errata, and testimonies that provide direct attribution to the enslaved and those that tried them. A supporting bibliography with additional mapping information can be used to develop one's own research projects, hypotheses, and literary endeavors. Users can thus trace the trajectory and the extent to which a certain piece of information circulated and hypothesize how it could have influenced or limited the conspiracies. Looking forward, the project would benefit from a collaborative tab that would allow users to share questions, data, and resources that might contribute to new interpretations. LSC, already an invaluable resource for research, could then function as its own research community.

LSC has received generous funding from the Berkeley Collaborative Research grant program, the Office of Digital Humanities at the National Endowment for the Humanities, the University of California Consortium for Black Studies in California, the University of California Humanities Research Institute, the Doreen B. Townsend Center for the Humanities, and the Center for the Gulf South at 
Tulane University. It has also attracted active interest at panel discussions alongside other projects such as Enslaved.org and Slave Voyages at the Lapidus Center Conference organized by the Schomburg Center of Research in Black Culture. 